\title{
9
}

\section{Determinants of household grain stocks}

\section{Does price matter?}

\author{
Guanghua Wan
}

China is the largest grain producer and consumer in the world. This fact underlies the enormous interest in the production and consumption of grains in China. In particular, the publications of Lester Brown (1995) led to worldwide comments, speculation and policy debate on the Chinese grain sector (Huang et al. 1996; Ministry of Agriculture 1996). It is estimated that some 60-70 per cent of annual output or 270-315 MMT of grains are held as household stocks in rural China. Needless to say, this volume and its changes could have profound implications on the design and implementation of domestic policies, such as price stabilisation and income-support schemes. For example, government retreat to a grain trade monopoly in China did not achieve expected outcomes in 1996-97. The stockpiling of state grain storage did not push up market prices because of the substantial grain stocks held by households and a general lack of understanding of farmers' grain storage behaviour.

Furthermore, household grain stocks also affect the demand for food imports and thus represent an essential ingredient of trade policymaking for the Chinese government and its trading partners (USDA 1994; OECD 1995b). To a large extent, national food security hinges on the volume and spatial distribution of grain stocks in rural China.

Despite the importance of grain stocks in China, little published work has appeared in the literature with exceptions of Zhong (1995) and Park (1996). This is a direct result of scarce or unavailable data.

Relying on household survey data compiled by the China Center for Agricultural Policy, the objective of this chapter is to identify determinants of household grain stocks in China. In particular, three sets of hypotheses are tested, each of which corresponds to a different motive of grain storage by 


\section{Determinants of household grain stocks in China}

Chinese farmers. Motives include price speculation, food security considerations and the minimisation of market transaction costs. To test these hypotheses, an adaptive-expectation and partial-adjustment model will be developed and applied to cross-sectional time-series data from China.

\section{A commodity storage model}

General commodity storage theory, which usually assumes that markets are operational and efficient, suggests that private storage can be explained by speculative behaviour (Williams and Wright 1991). Based on this theory, the desired level of grain stocks to be carried over to the next period, which is equivalent to the planned or desired stock level at the end of the current period, can be expressed as a function of expected price, formed for the next period

$$
S_{t}^{*}=f\left(P^{*}{ }_{t+1}\right)+u_{t}
$$

where $t$ indexes time period, $S^{*}$ denotes desired level of grain stocks at the end of period $t$, and $\mathrm{P}^{*}{ }_{\mathrm{t}+1}$ indicates the price which is expected to prevail in period $\mathrm{t}+1$.

It is important to note that the stock level at the end of the present period $S^{*}{ }_{t}$ does not depend on the expectation for this period's price $\mathrm{P}^{*}{ }_{\mathrm{t}}$ which was formed in the previous period. This is because at the present time, actual price $P_{t}$ is already observed or being realised. Consequently, information contained in $\mathrm{P}^{*}$ becomes obsolete in period $t$ except in forming future expectations. Decision making at time $t$ will be based on the current price $P_{t}$ and newly formed expectation on price for the next period $\mathrm{P}^{*}{ }_{t+1}$. This is why $\mathrm{P}^{*}{ }_{t+1}$ rather than $\mathrm{P}^{*}$, appears on the right-hand side of Equation 9.1. It can be shown that under adaptive expectations the same model (such as Equations 9.7 or 9.13) can be obtained with or without inclusion of $\mathrm{P}_{\mathrm{t}}$ in Equation 9.1. To reiterate, current (actual or planned) stock depends on current expectation for next period's price $\mathrm{P}^{*}{ }_{t+1}$, not previous expectation for this period's price $\mathrm{P}^{*}$.

Postulating that $\mathrm{f}$ is of a linear form, Equation 9.1 can be specified as

$$
S^{*}=a_{0}+a_{1} P_{t+1}^{*}+u_{t}
$$

Although Equation 9.1 is consistent with standard storage theory and is intuitively appealing, neither the planned stock $S^{*}$ nor expected price $\mathrm{P}^{*}$ are directly observable.

Taking advantage of the classic work of Nerlove (1958), price formation is assumed to follow the well known adaptive expectation process:

$$
\mathrm{P}^{*}{ }_{\mathrm{t}+1}=\mathrm{P}_{\mathrm{t}}^{*}+\mathrm{r}\left(\mathrm{P}_{\mathrm{t}}-\mathrm{P}^{*}\right)
$$

where $P_{t}$ indicates realised price in period t. Clearly, $P_{t}-P^{*}{ }_{t}$ represents errors in the previous expectation. According to Equation 9.3, the current expectation for next period price is equal to the previous expectation for this period price plus an expectation-error-correction term. Put another way, 


\section{Dilemmas of China's Growth in the Twenty-First Century}

speculators adjust their expectations over time based on the degree of accuracy or inaccuracy of their previous expectation. In the absence of expectation of any form, it should be held that $\mathrm{P}^{*}{ }_{t+1}=\mathrm{P}_{t}$ in Equation 9.3. This corresponds to $r=1$. Otherwise, a proportion of the past expectation error is factored into the present adjustment in expectation, that is, $0 \leq \mathrm{r} \leq 1$. The value of $\mathrm{r}$ is clearly case-dependent and is determined by empirical data. It is noted that the absence of adaptive expectation $(\mathrm{r}=1)$ can be treated as a hypothesis and can be tested.

On the other hand, storage level is assumed to follow the partial adjustment process such that

$$
S_{t}=S_{t-1}+k\left(S_{t}^{*}-S_{t-1}\right)
$$

That is, realised changes in the level of stocks $\left(S_{t}-S_{t-1}\right)$ is a fraction of desired/planned changes $\left(S_{t}^{*}-S_{t-1}\right)$. Complete realisation of desired changes is assumed not to take place because of certain costs or constraints, such as bad harvests, changed financial situation, various shocks to the market, and so on. Again, the fraction $\mathrm{k}(0 \leq \mathrm{k} \leq 1)$ is case-dependent and is to be determined by data. Of course, complete realisation implies absence of partial adjustment. In this case, $k=1$ in Equation 9.4 or $S_{t}=S^{*}$.

It is useful to point out that both adaptive-expectation and partialadjustment processes bring dynamics into the storage model. Alternatives to these dynamic specifications, such as rational expectations, are available in the literature. However, all are hypotheses themselves and there is no conclusive theoretical or empirical evidence to justify a preference for one over another. Adaptive expectations and partial adjustment are adopted in this chapter because of their popularity and will be tested later in the chapter.

To obtain an estimable version of Equation 9.2, manipulations of both Equations 9.3 and 9.4 are necessary. Starting from Equation 9.4, it is easy to solve for $S^{*}$ and equating the resultant expression with the right hand side of Equation 9.2:

or

$$
1 / \mathrm{kS}_{\mathrm{t}}+(1-1 / \mathrm{k}) \mathrm{S}_{\mathrm{t}-1}=\mathrm{a}_{0}+\mathrm{a}_{1} \mathrm{P}_{\mathrm{t}+1}^{*}+\mathrm{u}_{\mathrm{t}}
$$

$$
S_{t}=(1-k) S_{t-1}+k a_{0}+k a_{1} P_{t+1}^{*}+k u_{t}
$$

Using $\mathrm{L}$ to denote the lag operator, Equation 9.3 can be written as (see Judge et al. 1985)

$$
(1-(1-r) L) P^{*}{ }_{t+1}=r P_{t}
$$

Defining $b=1-r$ and multiplying Equation 9.6 by $(1-b L)^{-1}$ yields

$$
\mathrm{P}_{\mathrm{t}+1}^{*}=\mathrm{r}(1-\mathrm{bL})^{-1} \mathrm{P}_{\mathrm{t}}
$$

Substituting the above for $\mathrm{P}^{*}$ in Equation 9.5 produces

$$
S_{t}=(1-k) S_{t-1}+k_{0}+k a_{1} r(1-b L)^{-1} P_{t}+k u_{t}
$$

Multiplying both sides of Equation 9.7 by (1-bL) gives

$$
\mathrm{S}_{\mathrm{t}}(1-\mathrm{bL})=\mathrm{ka}_{1} \mathrm{rP}_{\mathrm{t}}+(1-\mathrm{bL})\left[(1-\mathrm{k}) \mathrm{S}_{\mathrm{t}-1}+\mathrm{ka}_{0}+\mathrm{ku}\right]
$$

or 


\section{Determinants of household grain stocks in China}

$S_{t}-b S_{t-1}=(1-k) S_{t-1}+k a_{0}+k a_{1} r P_{t}+k u_{t}-b(1-k) S_{t-2}-b k a_{0}-b k u_{t-1}$ This is equivalent to

$$
\begin{aligned}
\mathrm{S}_{\mathrm{t}} & =(1-\mathrm{k}+\mathrm{b}) \mathrm{S}_{\mathrm{t}-1}+\mathrm{b}(\mathrm{k}-1) \mathrm{S}_{\mathrm{t}-2}+(1-\mathrm{b}) \mathrm{k} \mathrm{a}_{0}+\mathrm{ka}_{1} \mathrm{r} \mathrm{P}_{\mathrm{t}}+\mathrm{ku}_{\mathrm{t}}-\mathrm{bku}_{\mathrm{t}-1} \\
& =\gamma_{1}+\gamma_{2} \mathrm{~S}_{\mathrm{t}-1}+\gamma_{3} \mathrm{~S}_{\mathrm{t}-2}+\gamma_{4} \mathrm{P}_{\mathrm{t}}+\mathrm{kV} \mathrm{V}_{\mathrm{t}}
\end{aligned}
$$

where $\gamma_{1}=(1-b) \mathrm{k} \mathrm{a}_{0}=\mathrm{rk} \mathrm{a}, \gamma_{2}=1-\mathrm{k}+\mathrm{b}=2-\mathrm{r}-\mathrm{k}, \gamma_{3}=\mathrm{b}(\mathrm{k}-1)=(1-\mathrm{r})(\mathrm{k}-$ 1), $\gamma_{4}=\mathrm{k} \mathrm{a}_{1} \mathrm{r}$ and $\mathrm{V}_{\mathrm{t}}=\mathrm{u}_{\mathrm{t}}-\mathrm{bu}_{\mathrm{t}-1}$ is the new disturbance term. After obtaining estimates of $\gamma_{2}$ and $\gamma_{3}$, it is possible to solve for estimates of $\mathrm{r}$ and $\mathrm{k}$ as $\mathrm{r}=1$ $0.5\left(\gamma_{2} \pm \tau\right)$ and $\mathrm{k}=1+0.5\left(-\gamma_{2} \pm \tau\right)$, where $\tau=\left(\gamma_{2}^{2}+4 \gamma_{3}\right)^{0.5}$. Estimates of $\alpha$ s can then be recovered. These estimates are not unique unless $\tau=0$.

Clearly, Equation 9.8 incorporates both adaptive expectations and partial adjustment. Absence of adaptive expectations (only partial adjustment prevails) is implied by $r=1$ or $b=0$. In this case, Equation 9.8 reduces to

$$
\begin{aligned}
S_{t} & =(1-\mathrm{k}) \mathrm{S}_{\mathrm{t}-1}+\mathrm{ka}_{0}+\mathrm{ka}_{1} \mathrm{P}_{\mathrm{t}}+\mathrm{ku}_{\mathrm{t}} \\
& =\delta_{0}+\delta_{1} \mathrm{P}_{\mathrm{t}}+\delta_{2} \mathrm{~S}_{\mathrm{t}-1}+\mathrm{ku}_{\mathrm{t}}
\end{aligned}
$$

where the definitions of new notations are self-explanatory. Conversely, the absence of partial adjustment (only adaptive expectations prevails) is implied by $\mathrm{k}=1$. In this case, Equation 9.8 reduces to

$$
\begin{aligned}
S_{t} & =b S_{t-1}+r a_{0}+a_{1} r P_{t}+u_{t}-b u_{t-1} \\
& =\beta_{0}{ }^{*}+\beta_{1} P_{t}+\beta_{2} S_{t-1}+V_{t}
\end{aligned}
$$

It is not difficult to show that if neither adaptive expectations nor partial adjustment exists, Equation 9.8 simply reduces to

$$
\mathrm{S}_{\mathrm{t}}=\mathrm{a}_{0}+\mathrm{a}_{1} \mathrm{P}_{\mathrm{t}}+\mathrm{u}_{\mathrm{t}}
$$

Therefore, fitting Equations 9.8-9.11 to a set of data enables construction of appropriate statistics to test various hypotheses. If Equation 9.11 is rejected in favour of Equation 9.8, either or both of adaptive expectations and partial adjustment should be maintained. Otherwise, none of these dynamic specifications are acceptable.

Conditional on the rejection of Equation 9.11, the hypothesis of $\gamma_{3}=0$ can then be tested. By definition, $\gamma_{3}=(1-\mathrm{r})(\mathrm{k}-1)$. Thus, rejecting $\gamma_{3}=0$ means $\mathrm{k} \neq 1$ as well as $\mathrm{r} \neq 1$. Thus, both dynamic specifications were prevalent. It is important to note that once Equation 9.11 is rejected $\mathrm{k}=1$ and $\mathrm{r}=1$ cannot occur simultaneously. As a consequence, accepting $\gamma_{3}=0$ implies mutual exclusion of the two forms of dynamic specifications.

When $\gamma_{3}=0$ is concluded, it is necessary to distinguish partial adjustment of Equation 9.9 from adaptive expectations of Equation 9.10. In theory, this can be accomplished by testing $\mathrm{r}=1$ or $\mathrm{k}=1$. However, $\mathrm{r}=1-0.5\left(\gamma_{2} \pm \gamma_{2}\right)$ and $\mathrm{k}=1+0.5\left(-\gamma_{2} \pm \gamma_{2}\right)$ under $\gamma_{3}=0$. In this case, it is not possible to distinguish $\mathrm{r}$ from $\mathrm{k}$. This lack of distinction is also evident if, ignoring the stochastic terms, Equations 9.9 and 9.10 are compared. However, Equations 9.9 and 9.10 do differ in the structure of the disturbance term. This difference provides a way of testing partial adjustment against adaptive expectations under 


\section{Dilemmas of China's Growth in the Twenty-First Century}

alternative assumptions for $u_{t}$. In particular, if $u_{t}$ is a white noise, $V_{t}$ and $k V_{t}$ would be $M A(1)$ while $k u_{t}$ remains a white noise. If $u_{t}$ is $A R(p), V_{t}$ and $k V$, would be $M A(p+1)$ while $k u_{t}$ remains $A R(p)$, where $p$ denotes the order of autocorrelation or moving average.

It is useful to point out that what distribution and properties $\mathrm{u}_{\mathrm{t}}$ really possesses is unknown and subject to numerous speculations. However, as mentioned by Rao and Miller (1971:169), it is often inevitable for one to take chances in econometrics. In other words, some maintained hypotheses would have to be introduced, particularly those relating to disturbance terms. A most common practice is to assume $A R(1)$ for $u_{t^{\prime}}$ If $A R(1)$ is accepted for the error terms in Equations 9.9 or 9.10 , partial adjustment rather than adaptive expectations should be adopted. This, in turn, implies that $r=1$ and $k=1-\gamma_{2}$.

\section{Grain storage motives in China and construction of the empirical model}

The model specified in the preceding section is based on speculative theory. Assumptions underlying Equation 9.8 are unlikely to be consistent with situations in less developed countries (LDCs) (Renkow 1990). Observations from China indicate that significant price fluctuations co-exist with consistently rising household grain stocks in China. Such a phenomenon calls for alternative explanations of determinants of grain stock levels in China, beyond those of Williams and Wright (1991).

\section{Motives for grain storage other than speculation}

In a recent contribution, Park (1996) proposed that consumption smoothing is a dominant factor underlying the storage behaviour of Chinese farmers. In more concrete terms, households hold grain stocks for two reasons that are associated with inefficient or incomplete markets (Park 1996). These include attaining a convenience yield or the minimisation of transaction cost and food security. When transactions costs for selling and buying grains are high, farmers may decide to store enough grain to meet their own consumption requirements before the next harvest. The benefit of holding their own grain for consumption purposes is called the convenience yield and is equal to the costs saved if all grains had to be sold after harvest from production and bought back later for consumption needs.

Also, farmers may store grain for food security reasons, such as to insure households against rising prices. Although both monetary savings and storage are forms of intertemporal income transfer, only storage can provide food security by shielding the household from price risks. This is particularly so in a country like China where markets are absent or localised and production or yield risk is 


\section{Determinants of household grain stocks in China}

often reinforced by price risks.

To account for the motive of transactions cost minimisation in our study, a variable indicating market development is clearly needed. Grain purchase from the free market can be used but its absolute value may not be a good indicator as small purchases may be due to small consumption demands for raw grain in better-off or more developed areas. Consequently, the ratio of grain purchase to total grain consumption is utilised to indicate market development. It is conceivable that when the ratio approaches zero, consumption is completely drawn from their own production or storage, indicating absence of grain market. On the other hand, if the ratio approaches one, all consumption needs are satisfied from the market, indicating a high level of marketisation of grain production.

In considering food security the inclusion of insurance substitutes in the empirical model are required. These are represented by household savings, wealth status and off-farm income. Household savings and off-farm income are liquid assets and they can be used to purchase grain for consumption if needed. It is important to point out that whatever variables are used as indicators of insurance substitutes, they must not be directly and positively correlated with grain production. Under normal circumstances, those with substantial savings or high non-farm income are expected to hold less grain for two reasons. First, high-income families usually feel less threatened by grain shortages and subsequently stock less. Second, wealthier individuals are less risk averse. Nonliquid wealth may not be easily converted to cash in rural China. However, the level of wealth will affect decisionmakers' attitudes towards risk. Thus, it is relevant to include household wealth in the model. The best indicator of household wealth status is the value of housing. The wealth variable is expected to have a negative coefficient.

Given the above arguments, it is obvious that some stocks, say $S_{\mathrm{p}}$, could be used for price speculation and the rest, say $S_{0}$, are attributable to other motives and other factors. Consequently, it is useful to rename $S_{\mathrm{t}}$ in the earlier discussions as $S_{p}$ and then set $S_{t}=S_{p}+S_{o}$. Defining $S_{o}=g(X)+u^{*}$, where $X$ is a vector of additional variables, the gain storage model for China can be written as

$$
\begin{aligned}
\mathrm{S}_{\mathrm{t}} & =\mathrm{S}_{\mathrm{p}}+\mathrm{S}_{0} \\
& =\gamma_{1}+\gamma_{2} \mathrm{~S}_{\mathrm{t}-1}+\gamma_{3} \mathrm{~S}_{\mathrm{t}-2}+\gamma_{4} \mathrm{P}+\mathrm{g}(\mathrm{X})+\mathrm{V}_{\mathrm{t}}^{*}
\end{aligned}
$$

As argued earlier, some of the variables in $\mathrm{X}$ are related to food security and transactions cost minimisation motives. Others in $\mathrm{X}$ are control variables to be discussed below. The new disturbance term $\mathrm{V}^{*}$ is assumed to possess the same properties as $\mathrm{V}$.

\section{Control variables}

In the complete absence of markets, all three motives discussed above become irrelevant. In this case, storage may simply represent a passive response to 


\section{Dilemmas of China's Growth in the Twenty-First Century}

grain output shocks. That is, fluctuations in grain production will simply translate into stock changes, so stock level will be highly correlated with output. Even under efficient but localised markets, as output increases, given the inelastic demand of basic food items, prices will drop, sales will be down and stock levels will rise. On the other hand, when output is low, prices will be high and farmers will tend to draw their supplies from stocks. It is necessary to account for cross-region differences in production capacity. For that purpose, a per capita output variable will be included in the model.

In a country as large as China, the amount of grain held by a household will depend on the length of time until the next grain harvest. For example, in regions where spring sowing is possible, the stocks required would be less for consumption needs than otherwise. Obviously, this is related to cropping patterns, which differ from region to region in China. In the south, multiple cropping is common so households may only store enough grain for six months' consumption needs, while nine to twelve-month stocks are needed in the north. A variable controlling for this effect is the multiple cropping index, which would be negatively related to stock levels.

Livestock activities are expected to affect storage levels as well, since they can transform extra grain into cash income or alternative food substitutes. Meanwhile, some farmers will not consume the locally produced staple crop in one of the seasons. This happens in areas where maize is grown mainly for feed. Therefore, even though there are more than one cropping seasons within a year, these farmers may hold just as much for various motives as a household with only one cropping season. To control for these, a variable indicating the scope of household livestock activities is included. It is worth noting that grain output and livestock activities differ substantially over time and across regions in China.

In the area north of the Yangtze River (the rice and wheat regions of Jiangsu, Anhui, Hubei and Sichuan) where tastes and preferences favour rice, almost all wheat is marketed. In other words, households in these regions would hold one year of grain for its convenience yield or food security, despite high levels of multi-cropping. Dummy variables (DJ, DA, DH and DS) will be incorporated to control for this pattern of consumption preference.

Another dummy variable, DD, is needed to account for the infamous reintroduction of the grain trade monopoly in 1996. A time trend variable, $T$, is included to capture factors such as economic reforms, changing macroeconomic environment such as more liberalised policies, gradually changing ideology, the learning-by-doing of market instruments, the increasing availability of information and improved infrastructure.

Because price speculation is conditional on market development, it is useful to include the interactive variable $\mathrm{MP}$, defined as $\mathrm{MxP}$, into the model. Inclusion of this variable is justified because it may help to confirm that speculation effects are stronger in more developed areas. 


\section{Determinants of household grain stocks in China}

\section{The empirical model}

Assuming g also takes a linear form, the standard storage model is to be extended by augmenting Equation 9.8 by $g(X)$, where (time index is dropped when there is no confusion)

$$
\begin{aligned}
\mathrm{g}(\mathrm{X})= & \delta_{4} \mathrm{M}+\delta_{5} \mathrm{I}+\delta_{6} \mathrm{~W}+\delta_{7} \mathrm{Q}+\delta_{8} \mathrm{HH}+\delta_{9} \mathrm{MCI}+\delta_{10} \mathrm{~L}+\delta_{11} \mathrm{DJ} \\
& +\delta_{12} \mathrm{DA}+\delta_{13} \mathrm{DH}+\delta_{14} \mathrm{DS}+\delta_{15} \mathrm{DD}+\delta_{16} \mathrm{~T}+\delta_{17} \mathrm{MP}+\mathrm{u}^{*}
\end{aligned}
$$

Given the above discussions and specification of $\mathrm{g}(\mathrm{X})$, the extended model becomes

$$
\begin{aligned}
\mathrm{S}_{\mathrm{t}}= & \gamma_{1}+\gamma_{2} \mathrm{~S}_{\mathrm{t}-1}+\gamma_{3} \mathrm{~S}_{\mathrm{t}-2}+\gamma_{4} \mathrm{P}_{\mathrm{t}}+\delta_{4} \mathrm{M}+\delta_{5} \mathrm{I}+\delta_{6} \mathrm{~W}+\delta_{7} \mathrm{Q}+\delta_{8} \mathrm{HH}+ \\
& \delta_{9} \mathrm{MCI}+\delta_{10} \mathrm{~L}+\delta_{11} \mathrm{DJ}+\delta_{12} \mathrm{DA}+\delta_{13} \mathrm{DH}+\delta_{14} \mathrm{DS}+\delta_{15} \mathrm{DD}+ \\
& \delta_{16} \mathrm{~T}+\delta_{17} \mathrm{MP}+\mathrm{V}^{*}
\end{aligned}
$$

In Equation 9.13, $\mathrm{M}$ indicates market development (as defined earlier), I indicates insurance substitutes (defined as per capita net income from all sources other than farming plus per capita savings), W indicates wealth status (defined as per capita housing value), $Q$ indicates production capacity (defined as per capita grain output), $\mathrm{HH}$ indicates household size (defined as number of family members). Household size ( $\mathrm{HH})$ is expected to have a negative impact on $S$ as dictated by economies of scale in food demand or requirement. $\mathrm{MCI}$ indicates cropping pattern (defined as the multi-cropping index), $\mathrm{L}$ indicates livestock activity (defined as output value from livestock) and a group of dummy variables are as defined earlier.

Corresponding to the standard storage model, and dependent on the absence or presence of dynamics, the extended model may take the form of either Equations 9.13 or $9.14-9.16$ as follows (disturbance terms are omitted). Absence of adaptive expectations produces

$$
\mathrm{S}_{\mathrm{t}}=\mathrm{a}_{0}{ }^{*}+\delta_{1} \mathrm{P}_{\mathrm{t}}+\delta_{2} \mathrm{~S}_{\mathrm{t}-\mathrm{I}}+\mathrm{g}(\mathrm{X})
$$

Absence of partial adjustment produces

$$
\mathrm{St}=\beta_{0}^{*}+\beta_{1} \mathrm{P}_{\mathrm{t}}+\beta_{2} \mathrm{~S}_{\mathrm{t}-1}+\mathrm{g}(\mathrm{X})
$$

If neither adaptive expectations nor partial adjustment exists, the extended model becomes

$$
S_{t}=a_{0}+a_{1} P_{t}+g(X)
$$

It is noted that parameters in Equations 9.13-9.16 have the same symbols as in Equations 9.8-9.11. However, they are not equivalent. The same notations are used for easy exposition.

\section{Hypotheses and hypotheses testing}

Having specified the model, it is appropriate to consider the hypotheses and their testing. The three sets of motives for household grain storage lead to three sets of hypotheses.

- $\mathrm{H}_{1}$ : absence of price speculation

As the expected price of grain rises (and it is expected to continue to 


\section{Dilemmas of China's Growth in the Twenty-First Century}

rise), households will not store more grain. In the absence of price speculation, $\mathrm{a}_{1}=0$ in Equation 9.1 and this is equivalent to $\gamma_{4}=0$ in Equations 9.8 or 9.13 . However, $\gamma_{4}=0$ is only a necessary but not sufficient condition for accepting $\mathrm{H}_{1}$. This is because $\gamma_{4}=\mathrm{ka}_{1} \mathrm{r}$ and $\mathrm{k}$ and/or $\mathrm{r}$ could be zero empirically, although in theory they are assumed to lie between zero and unity. Therefore, when $\gamma_{4}=0$ is accepted, it is necessary to recover the estimate of $a_{1}$ and test its significance.

- $\mathrm{H}_{2}$ : transactions cost minimisation

In areas where markets are poor, transactions costs would be high and there is a greater motive to hold grain for its convenience yield. As the market develops, transactions costs are likely to decline and people may become more reliant on markets to provide food. As a consequence, stock levels are likely to fall. To test this motive, it is necessary to derive the marginal effect of market development on stock levels as $\delta_{4}+\delta_{17} \mathrm{P}$ and simply test $\delta_{4}+\delta_{17} \mathrm{P}=0$ at the sample mean of $\mathrm{P}$ against $\delta_{4}+\delta_{17} \mathrm{P}<0$.

- $\mathrm{H}_{3}$ : food security consideration

By and large, farmers are risk averse (Anderson et al. 1977). Poorer farmers will be more risk averse and thus will hold more grain for food security. It is postulated that the higher the non-farming income and savings, the less the farmer fears food insecurity. One would expect $\delta_{5}<0$ and $\delta_{6}<0$. Absence of food security motive is given by $\delta_{5}=\delta_{6}=0$.

\section{Data issues and preliminary analysis}

It is common knowledge that Chinese data are often incomplete. This is particularly the case with market information. As price data are only available for 1987-97, this study is confined to that time span as far as empirical modelling is concerned. Currently there are 31 provinces and autonomous regions in China. However, price data for Xizhang (Tibet) and Xinjiang are incomplete. Chongqing became an autonomous city in 1996, so data for Chongqing will be merged with Sichuan. Similarly, data for Hainan will be merged with Guangdong. Thus, 26 provinces or regions are covered in this study.

Through the efforts of the China Center for Agricultural Policy, data on the required variables are compiled from various sources. With the exception of prices, most observations are available at the provincial level on a yearly basis from 1982 onwards. The free market price data are available separately on a monthly basis for rice, wheat, maize and soybean. However, the seasonality of agricultural production and trading dictates that prices for some months are 


\section{Determinants of household grain stocks in China}

non-existent. To obtain a yearly price indicator, a weighted average of monthly prices should be computed with trading volumes as the weights. Unfortunately, the absence of monthly volume data precludes such a possibility. As a consequence, a simple arithmetic average is used to convert monthly prices to yearly prices for each commodity. This is also the practice of statistical bureaus in China.

After the above conversion, there are still some price observations missing for some individual commodities and particular regions/years. Initially, it was thought that neighbouring prices could be used as proxies. However, it was found that prices in neighbouring regions do not always have similar values. This is understandable given the fragmented nature of markets in China. Price levels depend on transportation costs and local supply, demand and marketing conditions. Regional protection and trade blockages occur in China which also lead to price differences in different regions. Neighbouring regions, however, share similar price trends. This discovery prompts us to use extrapolation to fill in the small number of missing values for rice and wheat.

Across commodities, it was found that observed prices for different commodities display remarkably similar trends. When price levels are converted into price indices, the indices for rice, wheat and maize are almost equivalent in many cases. Clearly this is because prices for these products are highly correlated. Without such equivalence, aggregating prices across all products is necessary in order to obtain an overall grain price indicator. This would require trading volumes for various commodities that are only available for some years and only for rice and wheat. Under such equivalence, however, weighted averages based on major food items will be sufficient. Thus, a price index based on the prices of rice and wheat will be constructed and used as the regional grain price indicator. This was the practice undertaken by Renkow (1990) and Saha and Stroud (1994:528), who used the price of a major crop to represent the general grain price.

China's staple foods are rice and wheat and these are the grains farmers normally hold as stocks. Most southern regions grow rice while most northern regions grow wheat. However, there are many regions that grow and trade both. This is why the general grain price will be obtained as the weighted average of rice and wheat prices. The weights are based on the trading volumes of rice and wheat, averaged over the period 1987-97 for individual regions. The average is used because of the lack of complete time-series data on trading volumes.

It is noted that speculation can only occur in response to prices on the free market. Procurement prices are of little (if any) relevance in this context, as they are set once a year well before harvest and are known to not be subject to speculation. Although procurement prices are associated with the delivery quota, promises regarding both the price and quota have often proven to be empty. Only a small portion of grain produced is subject to government procurement where procurement prices may have relevance. 


\section{Dilemmas of China's Growth in the Twenty-First Century}

Observations on household stocks and other variables are available from various publications of the State Statistical Bureau (SSB, various years). Plots of the year-end stock data indicate that there is a general increasing trend in grain stock levels. This trend relates well to increases in grain outputs. Such a relationship is consistent with the fact that grain production in China is largely subsistent. The development of the market and increases in income may weaken this relationship. However, it will take time for farmers to learn how to use the market and change their ideology.

Preliminary data analysis reveals that substantial increases in stock levels occurred in 1994 and 1997 respectively, following increased outputs in 1993 and 1996. Similarly, an apparent drop occurred in 1996 for many regions. The drop clearly correlates with decreases in the production outputs in 1995. Drops in 1991 are likely to be a result of the substantially increased state purchase price even though grain output increased in 1990. On the other hand, 1985, 1988,1992, and 1994-95 saw drops in output which had little impact on stock levels, except in the last case.

There is clearly an asymmetric pattern relating output and stock levels. This asymmetry is attributable to two major factors. First, risk-sharing may have played a role. That is, farmers dispose of less grains in years of adverse harvest in order to maintain stock levels. Second, the lack of market development implies that isolated markets cannot be relied on for grain disposal. In years of adverse harvest, price may be high but food security can take prevalence over profit motives. Conversely, in years of good harvest more disposals are hindered by the absence of an efficient market. Even if the market is present and efficient, no profit exists for grain disposal.

Nevertheless, one would expect a convergence in the stock levels as the national economy moves towards integration and the farming sector becomes more commercialised. However, this is not clearly evident, as the cross-region differences in stock levels seem to have been maintained over years. One possible explanation lies in the habit of storing grains. As with other habits, it takes time for farmers to change their ideology and traditional practices even if markets are fully developed, let alone when the markets are largely isolated as in rural China.

Substantial inflation and deflation have occurred in China since the 1980s. Subsequently, it is important to deflate those observations in value terms. The regional consumer price indices (CPIs) compiled by Wan (2001) are to be used for this purpose.

\section{Model estimation and selection}

Given the availability of cross-sectional data, three approaches can be used to estimate the model. The first is the random effects or error components approach 


\section{Determinants of household grain stocks in China}

(Wan and Anderson 1990; Wan et al. 1992 for applications to China). The second is the so-called fixed effects or dummy variable approach (Fan 1991; Wan and Chen 2001). The third is the Kmenta procedure (Kmenta 1971). For applications to China, see Wan (1996a and 1996b).

There are no clear-cut conclusions as to which is the superior approach. Applied researchers choose an approach according to the research problem at hand and their individual preferences. The Kmenta procedure is used in this chapter, primarily because it accounts for both autocorrelations over time for each region and heteroscedasticity across regions. Meanwhile, this approach enables distinction between the partial adjustment and adaptive expectations, as discussed elsewhere in this chapter. The Kmenta procedure also converges to the maximum likelihood upon iterations.

Subsequently, Equation 9.13 was fitted to the Chinese data using the Kmenta procedure. Three versions of Equation 9.13 were obtained: (1) no autocorrelation was assumed at all. That is, the coefficient of autocorrelation $\rho=0$ for all regions; (2) the same autocorrelation was assumed (that is, AR(1) with an identical $\rho$ for all regions); and (3) different $\rho$ for different regions. Heteroscedasticity is always permitted.

By convention, it is necessary to devise a sequence of tests to aid model selection. Towards this end, a four-stage testing procedure is developed as shown in Figure 9.1. Since there exists no a priori knowledge on the error structure and hypothesis testing could be affected by the assumptions on the error structure, all tests are to be carried out under each of the three versions of Equation 9.13. Hopefully, this will help minimise the possibility of incorrect testing due to mis-specification of the disturbance term.

This procedure starts with testing the applicability of equation extensions proposed in this chapter. This is followed by testing the presence or absence of dynamics in the model. At the third stage, the specific form of dynamics (that is, partial adjustment and adaptive expectations co-exist or are mutually exclusive) is tested.

Finally, tests are used to choose between adaptive expectations and partial adjustment. It is noted that while jointly testing $\gamma_{2}$ and $\gamma_{3}$ is needed in assessing the presence or absence of dynamics (stage 2), the significance of parameter $\gamma_{2}$ becomes irrelevant at stage 3 . Nevertheless, unless both dynamics are supported by data, $\gamma_{3}=(1-r)(k-1)=0$ must be true (either $r=1$ and/or $\left.k=1\right)$. On the other hand, as long as one form of dynamics exists, then $\mathrm{k} \neq 1(\mathrm{r}=1)$ or $\mathrm{r} \neq 1$ $(\mathrm{k}=1)$. If this is the case, $0 \leq \mathrm{k}-1+\mathrm{r} \leq 1$ and $\gamma_{2}=1-(\mathrm{k}-1+\mathrm{r})$ must be between zero and one.

The first two stages can be accomplished by using Wald's Chi-square test. The test statistic is tabulated in Table 9.1. As indicated on the top panel of Table 9.1, in all cases the standard model is rejected. A major implication is that in LDCs, and particularly in China, the standard storage theory and 


\section{Dilemmas of China's Growth in the Twenty-First Century}

models are not applicable without modification. In other words, motives other than price speculation are important in explaining farmers' storage behaviour. The existence of partial adjustment and/or adaptive expectations behaviour is confirmed by the Chi-square values in the middle panel of Table 9.1. This is so at any level of significance and under all specifications of the error structure. Thus, dynamic forces play a role in determining household grain stocks in China.

The attempt to identify the actual form of dynamics proves to be difficult as t-tests (see bottom panel of Table 9.1) produce conflicting results depending on the structure of the error term. Under the most restrictive and the most general specifications, however, $\gamma_{3}=0$ cannot be rejected at the 5 per cent significance level. Further, the findings from stage 4 (Table 9.2) indicate that the most general specification (autocorrelation differs from region to region) is most preferred. Therefore, it is concluded that the empirical data do not support simultaneous existence of partial adjustment and adaptive expectations: only one dynamic specification is consistent with the observed behaviour.

Which dynamic specification is consistent with the data, partial adjustment or adaptive expectations? To address this question, it is necessary and sufficient to verify the structure of the disturbance term. In general, any test on the structure of the error term is necessary but insufficient for obtaining conclusive answers to the question. In this particular context, however, the test or tests would be sufficient simply because earlier tests have made it clear that the two dynamic specifications are mutually exclusive. Of course, it is impossible to exhaust all possible error structures for $u$. Attention has been confined to three possibilities: white noise, identical AR(1) and differing AR(1).

The relevant test statistic is essentially equivalent to a generalised likelihood ratio, as outlined in Mood et al. (1974:Section 5.1). If all regions have the same variance, an F-test rather than a Chi-square test should be used. The former possesses small sample properties while the latter is only valid

\section{Table 9.1 Model selection tests}

\begin{tabular}{|c|c|c|c|c|c|c|}
\hline \multicolumn{7}{|c|}{ Error structure } \\
\hline$H_{0}$ & \multicolumn{2}{|c|}{$u_{i t}=p_{i} u_{i t-1}+v_{i t}$} & \multicolumn{3}{|c|}{$\begin{array}{l}\qquad u_{i t}=\rho u_{i t-1}+v_{i t} \\
\text { Chi-square value }\end{array}$} & $u_{i t}=v_{i t}$ \\
\hline All $\delta s=0$ & 311.648 & $(-)$ & 196.778 & $(-)$ & 242.313 & $(-)$ \\
\hline$\gamma_{2}=\gamma_{3}=0$ & 119.331 & $(-)$ & 141.074 & $(-)$ & 163.784 & $(-)$ \\
\hline \multicolumn{7}{|c|}{ t-ratio } \\
\hline$\gamma_{3}=0$ & 1.243 & $(0.214)$ & 2.94 & $(0.003)$ & 1.692 & $(0.091)$ \\
\hline
\end{tabular}

Note: Figures in parentheses are levels of significance. 
Determinants of household grain stocks in China

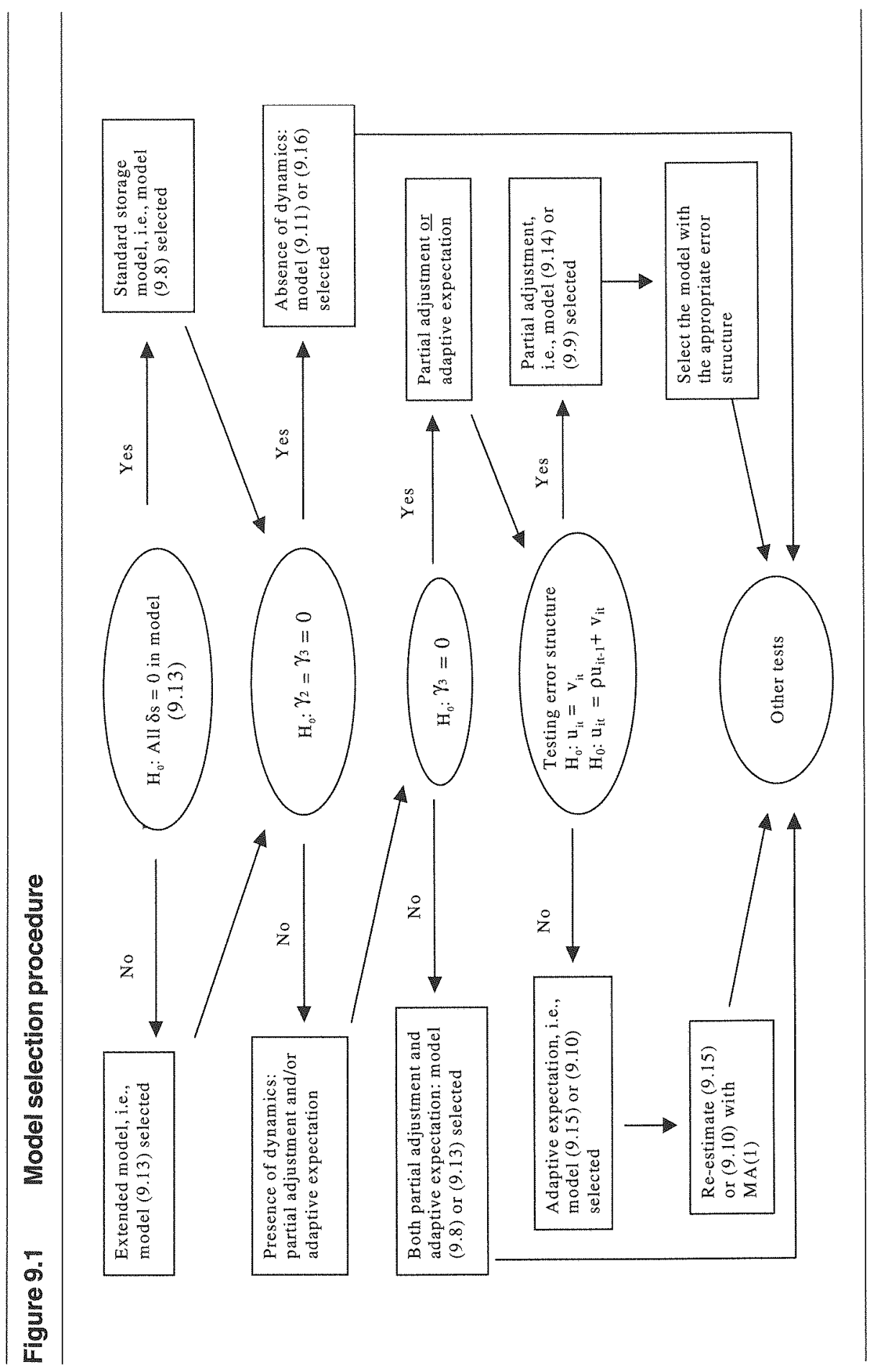




\section{Dilemmas of China's Growth in the Twenty-First Century}

asymptotically. Given the large sample size and the generality of the heteroscedasticity specification in the Kmenta procedure, the Chi-square test will be applied where possible.

Following Wan (1996b), the test statistic is simply $-2\left(\ln \lambda_{R}-\ln \lambda_{U}\right)$. The subscripts $R$ and $U$ stand for restricted and unrestricted models respectively and $\lambda$ s denote the relevant likelihood values. Given that there are 26 regions in the panel data, the degrees of freedom can easily be worked out (Table 9.2).

Absence of autocorrelation is rejected in favour of identical autocorrelation, which is in turn rejected in favour of different autocorrelation for different regions (Table 9.2). Further, AR(1) is accepted whether $\gamma_{3}=0$ or not. As discussed earlier, the acceptance of AR structure implies the acceptance of partial adjustment. Although heteroscedasticity is not tested, given the substantial differences in stock levels and vastly diverse socio-economic conditions across regions, it would be unreasonable to assume homoscedasticity.

In short, the model finally selected is the one with proposed augmentation, heteroscedasticity and differing $\rho$ for different regions. Because both dynamics do not prevail simultaneously, $\gamma_{3}$ must be set to zero in the final model. Further, acceptance of partial adjustment and rejection of adaptive expectations imply $\mathrm{k}=1-\gamma_{2}$ and $\mathrm{r}=1$ or $\mathrm{b}=0$.

\section{Results and discussions}

Estimation results based on the most preferred model are presented in Table 9.3. Judging from the Buse's $\mathrm{R}^{2}$, the model fits the data well. Most of the parameters are significantly different from zero except the wealth variable, which was included to account for the possible impacts of risk attitudes on stock levels. The signs of the estimates are all consistent with expectations, although one might argue for a negative coefficient for the variable of market development.

The marginal impact of market development on household stocks is given by $4.845-0.072 \mathrm{P}$, which would be less than zero as long as $\mathrm{P}$ is greater than 67.3. The sample average of the price variable is 57.25 . Thus, market development does not help reduce household stocks. A formal statistical test produced a Wald $\chi^{2}$-value of 2.14 which indicates that the market variable is not significant in explaining household storage decisions. Given this finding, the hypothesis of transactions cost minimisation is rejected. This rejection is unsurprising given that the level of household grain stocks has been consistently increasing despite the noticeable development of rural markets since the 1980s. From a theoretical perspective, the convenience yield concept is closely related to the opportunity cost of labour. When the opportunity cost is virtually zero (as in most rural areas of China), convenience yield will be negligible. This is probably why the hypothesis of transactions cost minimisation is rejected. 


\section{Determinants of household grain stocks in China}

Table 9.2 Model selection tests: testing error structure (cf. Figure 10.1)

\begin{tabular}{lcccc}
\hline & \multicolumn{2}{c}{ Chi-square value } & Degrees of freedom & Critical value \\
$\gamma_{3}: u_{i t}=v_{i t}$ & $\gamma_{3}=0$ & & 1 & 13.84 \\
(test size $=5 \%$ )
\end{tabular}

\section{Table 9.3 Estimation results}

\begin{tabular}{lccc}
\hline Variable & Estimate & $\begin{array}{c}\text { Asymptotic } \\
\text { T-ratio }\end{array}$ & $\begin{array}{l}\text { Level of } \\
\text { significance }\end{array}$ \\
St- ${ }_{1}$ & 0.456 & 11.530 & - \\
P & 0.920 & 2.041 & 0.041 \\
M & 4.845 & 2.604 & 0.009 \\
I & -0.080 & -3.833 & - \\
Q & 0.392 & 14.070 & - \\
HH & -33.136 & -4.615 & - \\
MCl & -78.748 & -8.150 & - \\
L & 0.256 & 2.190 & 0.028 \\
W & -6.862 & -0.140 & 0.888 \\
P*M & -0.072 & -2.287 & 0.022 \\
Time trend & 4.860 & 4.854 & - \\
Dummies & & & \\
DA & -21.795 & -0.952 & 0.341 \\
DJ & -34.724 & -3.537 & - \\
DH & -53.463 & -5.747 & - \\
DS & -17.875 & -1.769 & 0.077 \\
DD & -78.442 & -9.662 & - \\
Constant & 219.400 & 3.967 & - \\
Buse R ${ }^{2}=0.947$ & $B u s e$ Raw-moment $R^{2}=0.993$ & \\
& & & \\
\hline
\end{tabular}




\section{Dilemmas of China's Growth in the Twenty-First Century}

This rejection also means that food security and price speculation dominate the motives of grain storage in rural China.

Food security motives are related to income and wealth variables. Both are associated with negative coefficient estimates that signal the acceptance of the hypothesis of food security consideration. The coefficient of the income variable is significant while the wealth variable is insignificant. This insignificance is perhaps unsurprising given the level of data aggregation. Household-level data are better in assessing the impact of diminishing risk aversion in general.

To analyse the price effect, the marginal impact of the price variable is needed. This is given by $0.92-0.072 \mathrm{M}$. Since $M \leq 1$ by definition, increases in (expected) prices lead to increases in storage levels. To confirm the speculative motive, it is useful to recover the estimate of $\alpha_{1}$ and compute its standard error. Referring to the definitions below Equation 9.8 and given that $\mathrm{r}=1$ and $\mathrm{k}=1-\gamma_{2}$, it is easy to find that $\alpha_{1}=\gamma_{4} /\left(1-\gamma_{2}\right)$. Its asymptotic variance can be obtained as $\operatorname{Var}\left(\gamma_{4}\right) / \mathrm{k}^{2}+\operatorname{Var}\left(\gamma_{2}\right)\left(\gamma_{4} / \mathrm{k}^{2}\right)^{2}-2 \operatorname{Cov}\left(\gamma_{2}, \gamma_{4}\right) / \mathrm{k}^{3}$. The estimate of the parameter is 1.69 and that of the standard error is 0.93 . This value is positive and statistically significant, implying the existence of speculative motive. In fact, more market-developed areas are associated with smaller responsiveness to price changes. This may imply the localised nature of markets in less developed areas.

The estimates of $k, \alpha_{1}$ and $\alpha_{0}$ are found to be $0.544,1.69$ and 403.31 respectively. The positive signs and magnitudes of these estimates are not inconsistent with a priori expectations. It is interesting to note that the estimated value of $k$ is 0.544 which lies in the range $(0,1)$. The significance of $\gamma_{2}$ implies the significance of $\mathrm{k}$, which in turn provides further support for the dynamic specification of partial adjustment.

As expected, most of the control variables are significant. In particular, local production capacity is positively related to stock levels. This implies that to a large extent, supply shocks are absorbed by grain storage. The estimated coefficient suggests that about $0.4 \mathrm{~kg}$ of grain would be stored following every $1 \mathrm{~kg}$ increase in production. Similarly, multiple cropping exerts quite a large and significant negative impact on household stocks.

\section{Summary}

To answer the question posed in the title of the chapter, price does matter. That is, rural farmers in China do engage in speculative activities. In fact, the more developed the grain markets, the more active the speculative activities, thus the smaller the marginal price impact. A secondary finding is that households in rural China tend to adjust their stock levels based on partial 


\section{Determinants of household grain stocks in China}

adjustment dynamics, not adaptive expectations. Food security but not transactions cost consideration affects farmers' grain storage behaviour as well.

Alternative frameworks including system approaches are not adopted due to the lack of data and associated assumptions of complete product and factor markets. The ad hoc specification used here is a direct result of the unavailability of data, which prevents us from modelling household behaviour in an optimising and system framework. The maintained hypothesis of optimisation may not be compatible with reality in China given the subsistence nature and backward product and factor markets (see Rabin 1998 for inadequacy of existing utility theory). The optimising model comes with further costs. For example, the linear production function is often assumed to simplify the system model and make the model empirically estimable (Saha 1994; Park 1996).

Saha and Stroud (1994) proposed a model where consumption, storage and labour supply are estimated jointly as SUR. However, it is well known that SUR with identical regressors, as in Saha and Stroud (1994) can be estimated separately. In other words, our focus on the storage equation is unlikely to suffer from system equation bias.

\section{Acknowledgments}

This report is prepared under the support of the China Center for Agricultural Policy. I wish to thank Professor Jikun Huang (Director), Professor Linxiu Zhang (Deputy Director) and Professor Scott Rozelle of University of California for various inputs into the research. 